\title{
Critical Evaluation of Sinonasal Disease in 64 Adults with Primary Ciliary Dyskinesia
}

\author{
Emilie Bequignon ${ }^{1,2,3,4,+}$, Laurence Dupuy ${ }^{1,+}$, Francoise Zerah-Lancner $1,2,3,5 \mathbb{D}$, \\ Laurence Bassinet $^{1}$, Isabelle Honoré 6,7, Marie Legendre 8,9 ${ }^{\mathbb{D}}$, Marie Devars du Mayne ${ }^{1}$, \\ Virginie Escabasse 1,2,3 (D), Bruno Crestani 10,11,12,13 (D), Bernard Maître 1,2,3 ${ }^{1}$, Estelle Escudier ${ }^{8,9,+}$, \\ André Coste 1,2,3,4,+ and Jean-François Papon $2,4,14,15, *,+$
}

1 AP-HP, Hôpital Henri-Mondor-A Chenevier et Hôpital intercommunal, Services d'ORL et de Pneumologie, Créteil 94010, France; emilie.bequignon@gmail.com (E.B.); laurencedupuy@hotmail.fr (L.D.); francoise.zerah@aphp.fr (F.Z.-L.); kilad@orange.fr (L.B.); mariedevars@gmail.com (M.D.d.M.); Virginie.Escabasse@chicreteil.fr (V.E.); bm.maitre@gmail.com (B.M.); andre.coste@chicreteil.fr (A.C.) INSERM, U955, Créteil 94010, France

Université Paris-Est, Faculté de Médecine, Créteil F-94010, France

CNRS, ERL 7000, Créteil 94010, France

AP-HP, Hôpital Henri-Mondor-A Chenevier, Service De Physiologie et d'explorations Fonctionnelles, Créteil 94010, France

6 Assistance Publique-Hôpitaux de Paris, Hôpital Cochin, Service de Pneumologie, Paris 75014, France; isabelle.honore2@aphp.fr

7 Université Paris Descartes, Sorbonne Paris Cité, Paris 75006 France

8 Service de Génétique et Embryologie Médicales, Hôpital Armand-Trousseau, Assistance Publique-Hôpitaux de Paris, Paris 75012, France; marie.legendre@aphp.fr (M.L.); estelle.escudier@aphp.fr (E.E.)

9 INSERM, Unité Mixte de Recherche S933, Université Pierre et Marie Curie, Paris 75005, France

10 Maladies pulmonaires Rares (DHU FIRE) Service de Pneumologie A, Assistance Publique-Hôpitaux de Paris (AP-HP), Hôpital Bichat, Paris 75877, France; bruno.crestani@aphp.fr

11 Laboratoire d'Excellence Inflamex, Paris 75013, France

12 Université Paris Diderot, Sorbonne Paris Cité, Paris 75013, France

13 INSERM, Unité 1552, Paris 75013, France

14 AP-HP, Hôpital Kremlin-Bicetre, Service d'ORL et de Chirurgie Cervico-Faciale, Le Kremlin-Bicêtre 94275, France

15 Université Paris-Sud, Faculté de Médecine, Kremlin-Bicêtre F-94070, France

* Correspondence: jean-francois.papon@aphp.fr; Tel.: +33-145-213-681

+ These authors contributed equally to this manuscript.

Received: 14 March 2019; Accepted: 1 May 2019; Published: 7 May 2019

Abstract: To date, no study precisely described ear, nose and throat (ENT) disease in adults with primary ciliary dyskinesia (PCD) and its relationship with ciliary function/ultrastructure. A retrospective study of standardized ENT data (exam, audiogram, sinus Computed tomography (CT), and bacteriology) was conducted in 64 adults with confirmed PCD who were followed in two ENT reference centers. Rhinorrhoea and hearing loss were the main symptoms. Symptom scores were higher in older patients. Nasal endoscopy was abnormal in all patients except one, showing nasal polyps in one-third of the patients and stagnant nasal mucus secretions in $87.5 \%$ of the patients. Sinus CT opacities were mainly incomplete and showed one-third of the patients with sinus hypoplasia and/or agenesis. Middle meatus mainly grew Haemophilus influenzae, Streptoccocus pneumoniae and Pseudomonas aeruginosa. Otitis media with effusion (OME), which is constant in childhood, was diagnosed in less than one-quarter of the patients. In two-thirds of the patients, audiogram showed hearing loss that was sensorineural in half of the patients. ENT disease severity was not correlated with ciliary function and ultrastructure, but the presence of OME was significantly associated with a forced expiratory volume (FEV1) $<70 \%$. Rhinosinusitis is the most common clinical 
feature of PCD in adults, while OME is less frequent. The presence of active OME in adults with PCD could be a severity marker of lung function and lead to closer monitoring.

Keywords: airway mucociliary clearance; chronic rhinosinusitis; Kartagener syndrome; otitis media with effusion; primary ciliary dyskinesia

\section{Introduction}

Primary ciliary dyskinesia (PCD) is a rare autosomal recessive inherited disorder affecting approximately 1:10,000 to 1:30,000 individuals [1]. The pathophysiology of PCD is characterized by defects in airway mucociliary clearance, predisposing affected individuals to recurrent respiratory infections and leading to symptoms typically present since birth [2]. Approximately half of sufferers have situs inversus (SI) [3,4] and a majority of male patients are infertile [5]. One subgroup of patients with PCD have an array of chronic rhinosinusitis, bronchiectasis, and SI, called Kartagener syndrome (KS).

Otologic presentation has been well described in children [4,6,7]. Early in childhood, the main clinical feature is severe and binaural otitis media with effusion (OME) leading to hearing impairment and causing delays in speech acquisition. Otologic disease tends to improve with age [4] while the sinonasal disease persists and may increase [3,8]. In children, some authors have reported nonspecific rhinological symptoms such as nasal discharge and episodic facial pain resulting in chronic rhinosinusitis [3]. Hypoplasia and agenesis of paranasal sinus have also been described.

To date, no study has precisely assessed ear, nose and throat (ENT) disease, clinical features, and the relationship between ENT manifestations and ciliary function/ultrastructure in adults with PCD. In this study, we aimed to evaluate the upper airway phenotype by describing ENT disease in adults with PCD, who were followed in two French reference ENT centers.

\section{Experimental Section}

\subsection{Patients and Methods}

We performed a retrospective study in PCD patients followed in two ENT departments (Mondor Hospital and Intercommunal of Creteil) both of which are members of the French National Reference Centre for Rare Respiratory Diseases (RespiRare).

\subsection{Study Population}

Inclusion criteria was a confirmed diagnosis of PCD and age $>18$ years at the start of the ENT followup in the reference centers. All patients had bronchiectasis on a computed tomography (CT) scan. Patients with other pathological conditions, such as cystic fibrosis (CF) or immunodeficiency, were excluded. We considered that a patient had a confirmed diagnosis of PCD when at least one or more of the following criteria was present: (i) a clinical diagnosis of KS, (ii) evidence of PCD-specific ciliary ultrastructural defects, and (iii) identification of non-ambiguous causal mutations in a known PCD gene. All patients had measurements of the ciliary beat frequency (CBF) and analysis of ciliary ultrastructure as described previously [9-11]. Nasal nitric oxide (nNO) was also measured as previously described [12].

The Ethics Review Board of RespiRare approved the retrospective use of the database register on March 20, 2008 (CCTIRS, no.08.015bis).

\subsection{Data Collection}

For each patient, the following variables were recorded at the time of the first ENT visit in the ENT reference center: demographic data (age, sex, geographical origin, active smoker), neonatal respiratory 
distress, abnormalities of organ lateralization, fertility disorders, and other features potentially related to PCD (retinitis pigmentosa, polycystic kidney, obesity, and psychomotor retardation). All declarative history of consanguinity, and familial PCD, ENT or respiratory disease was noted. Lung characteristics included symptoms, a history of bronchiectasis and/or asthma, and lung surgery. Results of forced expiratory volume after one second $\left(\mathrm{FEV}_{1}\right), \mathrm{nNO}, \mathrm{CBF}$, ciliary ultrastructure and genetic molecular analyses were recorded.

\subsection{Standardized ENT Evaluation}

Throughout the study period, an ENT evaluation was performed during a routine visit in our reference center by the same two senior investigators which included a systematic microscopic examination of the ears and a nasal endoscopy. The clinical ENT observed data were reported during the first visit included nose (i.e., congestion, rhinorrhea, anosmia, hyperreactivity, and pain) and ear (i.e., hearing loss, earache, tinnitus, and otorrhoea) symptoms. Six nasal functional criteria were determined: nasal congestion, rhinorrhea, dysosmia, nasal hyperactivity (itching and pruritus), facial pain, and epistaxis. The severity of each symptom was evaluated by the senior investigator according to a 4-point semi-quantitative scale: 0 , no symptoms; 1 , moderate symptoms; 2 , mild symptoms that slightly interfere with daily activities or sleep; and 3, severe symptoms that severely interfere with daily activities or sleep. For each patient a global functional score was calculated by adding the scores of the 6 functional criteria, with a maximum of 18 [13,14]. A standardized nasal endoscopic evaluation was performed by a single clinician during the routine visit including the following findings: the presence of erythema, polyps, mucosal oedema, secretion discharge (purulent or not), and crusting. In the case of purulent nasal secretions (patients were not systematically symptomatic or having an exacerbation), a sample was obtained under endoscopic view by aspiration in the middle meatus with a sterile tube in order to perform a bacteriological analysis. A pure tone audiogram was performed in patients with an abnormal eardrum and/or complaining of hearing loss. All tested patients underwent tympanometry and audiometric tests which including pure tone audiometry (PTA) with both air and bone conduction at frequencies of 250, 500, 1000, 2000, 4000, and $8000 \mathrm{Hertz}(\mathrm{Hz})$. In the case of a hearing loss that was $20 \mathrm{~dB}$ or less, hearing was considered normal or subnormal. In the case of a hearing loss that was greater than $20 \mathrm{~dB}$, we classified hearing loss into 3 groups: sensorineural, conductive, or mixed hearing loss. Sensorineural hearing loss was defined as having equal air and bone conduction decrease thresholds greater than $20 \mathrm{~dB}$. Air-bone gaps greater than $10 \mathrm{~dB}$ were considered as conductive or mixed hearing loss. ENT treatments before diagnosis and during followup in the center were listed.

\subsection{Sinonasal CT Evaluation}

Data from CT scans of the paranasal sinuses (when available) included: (i) the Lund-Mackay CT score [15] modified according to the prevalence of sinus aplasia [15], and (ii) the degree of pneumatization of each paranasal sinus according to radiological criteria recently used in adults with cystic fibrosis [16]. The degree of pneumatization of each paranasal sinus was evaluated by the same radiologist.

\subsection{Statistical Analyses}

All analyses were performed using the statistical software package (Statview 4, SAS Institute, Grenoble, France).

We determined the ENT characteristics of the patients at the first visit in our center. The quantitative variables were expressed as a mean (SD) or median (range) when appropriate and the qualitative variables were expressed as a number (percentage).

At the first ENT visit in our reference center, nasal disease (mean overall nasal score, sinonasal CT score) and ear disease (presence of OME) were each separately compared to the lung function and PCD diagnostics features (nNO values, $\mathrm{CBF}$, the ultrastructural phenotype) 
Using the unpaired t-test, we compared the quantitative data (i.e., mean overall nasal score and $\mathrm{CT}$ score) between two groups according to the FEV1 ( $\mathrm{FEV}_{1}<70 \%$, or $\mathrm{FEV}_{1} \geq 70 \%$ ), or to the $\mathrm{nNO}$ values $(<77 \mathrm{~nL} / \mathrm{min}$ and $\geq 77 \mathrm{~nL} / \mathrm{min}$ ), or to the $\mathrm{CBF}$ (normal CBF ( $>8 \mathrm{~Hz}$ ) or abnormal CBF (defined as complete immotility or low $\mathrm{CBF}<8 \mathrm{~Hz}$ ) The mean overall score of nasal symptoms at diagnosis was also compared between two groups ( $<40 \mathrm{vs} \geq 40$ years) using the unpaired t-test.

A comparison of quantitative data according to the ultrastructural phenotype, which was classified in three groups, (i.e., no detectable defect, $\mathrm{CC}=$ Central complex abnormalities; DA $=$ dynein arms abnormalities) respectively, was made using an analysis of variance (ANOVA).

The Chi-Squared statistic was used for testing relationships between the presence (or absence) of OME and: $\mathrm{FEV}_{1}(<70 \%$ or $\geq 70 \%)$, age ( $<40 \mathrm{vs} \geq 40$ years), $\mathrm{nNO}(<77 \mathrm{~nL} / \mathrm{min}$ and normal $\mathrm{nNO}$ $\geq 77 \mathrm{~nL} / \mathrm{min}$ ), CBF (normal or abnormal), or the ultrastructural phenotype.

The correlation between age and nasal symptoms was studied using the Spearman's test.

Statistical significance was accepted for $p<0.05$.

\section{Results}

\subsection{Study Population}

Sixty-four adult patients (40 males and 24 females) with a confirmed diagnosis of PCD, from 59 independent families, were included. In the case of typical KS with SI and/or neonatal respiratory distress, the mean age $( \pm \mathrm{SD})$ at diagnosis was $16.5 \pm 15$ years. For the remaining patients, the mean age at diagnosis was $30 \pm 14$ years. Patient characteristics are reported in Table 1 . The mean age $( \pm \mathrm{SD})$, at the first ENT visit in the center was $32 \pm 11$ years. The median value of $\mathrm{nNO}$ (range) was $16(1-634) \mathrm{nL} / \mathrm{min}$ and $84.4 \%$ of patients had an $\mathrm{nNO}$ lower than $77 \mathrm{~nL} / \mathrm{min}$ (supplementary data Table S1). In three patients, $\mathrm{n}$ NO was $>200 \mathrm{~nL} / \mathrm{min}$. Transmission electron microscope (TEM) analysis was performed in 62 patients and ultrastructural defect was identified in $90.3 \%$ of them (supplementary data Table S1). Molecular analysis was available in 58 patients and causal biallelic mutations in a known PCD gene were identified in $77 \%$ of them. Lung characteristics are described in Table 1. Bronchiectasis were present in all patients (100\%). A $\mathrm{FEV}_{1}<70 \%$ was reported in $50 \%$ of patients.

\subsection{Description of the Sinonasal Disease}

Sixty-three patients (98.4\%) had a history of recurring problems at the paranasal sinuses (Table 2). All patients had at least one sinonasal symptom (Table 2). Rhinorrhoea was the most frequent symptom ( $n=61$ or $95.3 \%$ of the patients). At diagnosis, the mean overall score of nasal symptoms was $5.6 \pm 2.7$ (media $n=6$, range 1-12) and higher in the $\geq 40$-year subgroup (mean $6.5 \pm 3.1$ ) compared to the $<40$-year subgroup (mean $5 \pm 2.3)(p=0.04$, student). There was a significant correlation between age and nasal symptom score ( $r=0.2, p=0.02$, Spearman) (Figure 1). Only one patient had a normal nasal endoscopic examination. The most frequent endoscopic abnormalities were oedema and congestion of nasal mucosa ( $n=9$ or $14 \%$ of the patients and $n=28$ or $43.7 \%$ of the patients, respectively). Polyps were observed in 22 patients (34.4\%). Stagnant nasal mucus secretions were present in 56 patients (87.5\%) with purulent secretions in $55.3 \%$ of them. In 35 patients (54.7\%) we observed sticky secretions that were strung between the septum and the inferior turbinates (Figure 2). Bacteriological culture of the middle meatus was performed in 31 patients and showed one or more bacteria in $83.9 \%(n=26)$. The most common bacteria were Haemophilus influenza (25.8\%), Pseudomonas aeruginosa $(19.3 \%)$, and Streptococcus pneumonia (19.3\%). A sinus CT scan was available for 41 patients showing agenesis and/or hypoplasia (mainly frontal sinus) in 15 patients (36.6\%) (Figure 1). Sinus opacities were present in 36 patients (89\%) (Figure 1). A normal sinus CT scan was observed in five patients (12.2\%). The mean CT score was $6.2 \pm 3.6$. No complications such as mucocele were reported. Thirty-seven patients $(57.8 \%)$ had a history of sinonasal surgery before the first ENT visit to the reference centre. Sinonasal treatments at diagnosis are reported in Table 2. The main nasal treatments initiated after diagnosis included 
meticulous nasal rinsing with daily isotonic saline (twice daily) for $83 \%$ of the patients and local corticosteroids for $62 \%$ of the patients. After diagnosis, sinonasal surgical treatment was performed in $19 \%$ of the patients. Surgery concerned the ethmoidal and/or frontal sinuses $(40 \%)$, maxillary sinuses $(10 \%)$, turbinates $(35 \%)$, polyps $(5 \%)$, and septum $(5 \%)$.

Table 1. Primary ciliary dyskinesia (PCD) patient characteristics ( $n=64$, except when specified).

\begin{tabular}{|c|c|c|}
\hline Characteristics & & \\
\hline & Mean & $\pm \mathrm{SD}$ \\
\hline \multirow[t]{2}{*}{ Age at the first ENT visit in our center (years) } & 32 & 11 \\
\hline & Patient $(n)$ & $\%$ \\
\hline \multicolumn{3}{|l|}{ Gender } \\
\hline Female & 24 & 37.5 \\
\hline Male & 40 & 62.5 \\
\hline \multicolumn{3}{|l|}{ PCD related diseases } \\
\hline Neonatal respiratory distress & 18 & 28.1 \\
\hline Situs inversus & 22 & 34.3 \\
\hline Heterotaxy & 4 & 6.2 \\
\hline Fertility disorders & 36 & 56.2 \\
\hline Retinitis pigmentosa & 3 & 4.7 \\
\hline Polycystic kidney disease & 2 & 3.1 \\
\hline Family history ( $n=59$ independent families) & Families $(n)$ & \\
\hline Consanguinity & 18 & 30.5 \\
\hline PCD * & 11 & 18.6 \\
\hline Situs inversus & 4 & 6.8 \\
\hline Rhinosinusitis & 15 & 25.4 \\
\hline Otitis & 9 & 15.2 \\
\hline Asthma & 9 & 15.2 \\
\hline Bronchiectasis & 9 & 15.2 \\
\hline \multicolumn{3}{|l|}{ Lung diseases } \\
\hline Asthma & 14 & 22 \\
\hline Bronchiectasis & 64 & 100 \\
\hline \multicolumn{3}{|l|}{ Lung surgery } \\
\hline Lobectomy & 15 & 23.4 \\
\hline Transplantation & 1 & 1.6 \\
\hline \multicolumn{3}{|l|}{ Lung function test $n=45$} \\
\hline FEV1/FVC $\%$ mean \pm SD (range) & \multicolumn{2}{|c|}{$73.6 \pm 13.8(47-100)$} \\
\hline FEV1 $\%$ mean \pm SD (range) & \multicolumn{2}{|c|}{$72.7 \pm 24.7(18-128)$} \\
\hline
\end{tabular}

Abbreviations FEV1 = forced expiratory volume; FVC = forced vital capacity; SD = standard deviation. * Family history of PCD: All the other family members who had PCD were siblings except one case (the other family member who also had PCD was the mother of the patient).

\section{Distribution of the nasal symptoms score according to the age and ciliary abnormalities}

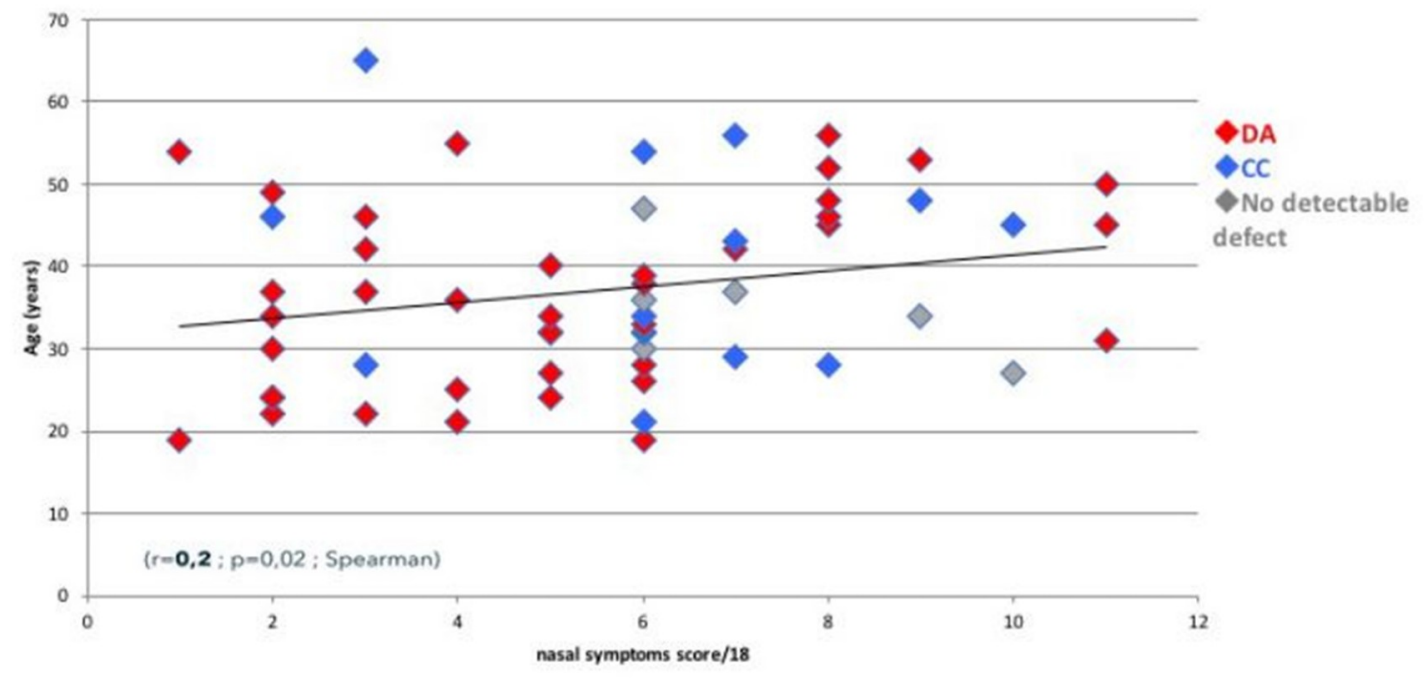

Figure 1. Distribution of nasal symptoms score according to the age and ciliary abnormalities. Abbreviations: $\mathrm{CC}=$ central complex abnormalities; DA = dynein arms abnormalities. 
Table 2. Sinonasal disease characteristics at diagnosis in our reference center $(n=64)$.

\begin{tabular}{cccc}
\hline & Patient (n) & & \\
\hline History of Sinonasal Surgery before the First ENT Visit in our Reference Center \\
\hline Unspecified surgery & 22 & 34.4 & \\
Middle meatotomy & 9 & 14.1 & \\
Ethmoidectomy & 8 & 12.5 & \\
Turbinate reduction & 8 & 12.5 & Score of severity *: mean \\
Polypectomy & 1 & 1.6 & \pm SD (range) \\
\hline Sinonasal symptoms & & & $1.9 \pm 0.8(0-3)$ \\
Rhinorrhoea & 61 & 95.3 & $1.3 \pm 1.1(0-3)$ \\
Congestion & 42 & 65.6 & $1 \pm 0.9(0-3)$ \\
Facial pain & 35 & 54.7 & $0.2 \pm 0.6(0-3)$ \\
Dysosmia & 35 & 54.7 & $0 \pm 0.2(0-1)$ \\
Nasal hypereactivity & 9 & 14.1 & \\
Epistaxis & 4 & 6.2 & \\
\hline Nasal endoscopy & & & \\
\hline Inferior turbinate & & & \\
Normal & 33 & 51.6 & \\
Hypertrophy & 22 & 34.4 & \\
Atrophy/scar & 10 & 15.6 & \\
\hline Nasal mucosa & & \\
Normal & 13 & 20.3 & \\
Congestion & 28 & 43.7 & \\
Edema & 9 & 14 & \\
Polyps & 22 & 34.4 & \\
\hline Nasal secretions & & & \\
Normal & 35 & 54.7 & \\
Sticky & 21 & & \\
Purulent & & & \\
\hline
\end{tabular}

Legends: * The severity of each symptom was evaluated according to a 4-point semi-quantitative scale: 0 , no symptoms; 1 , moderate symptoms; 2 , mild symptoms that slightly interfere with daily activities or sleep; and 3, severe symptoms that severely interfere with daily activities or sleep.
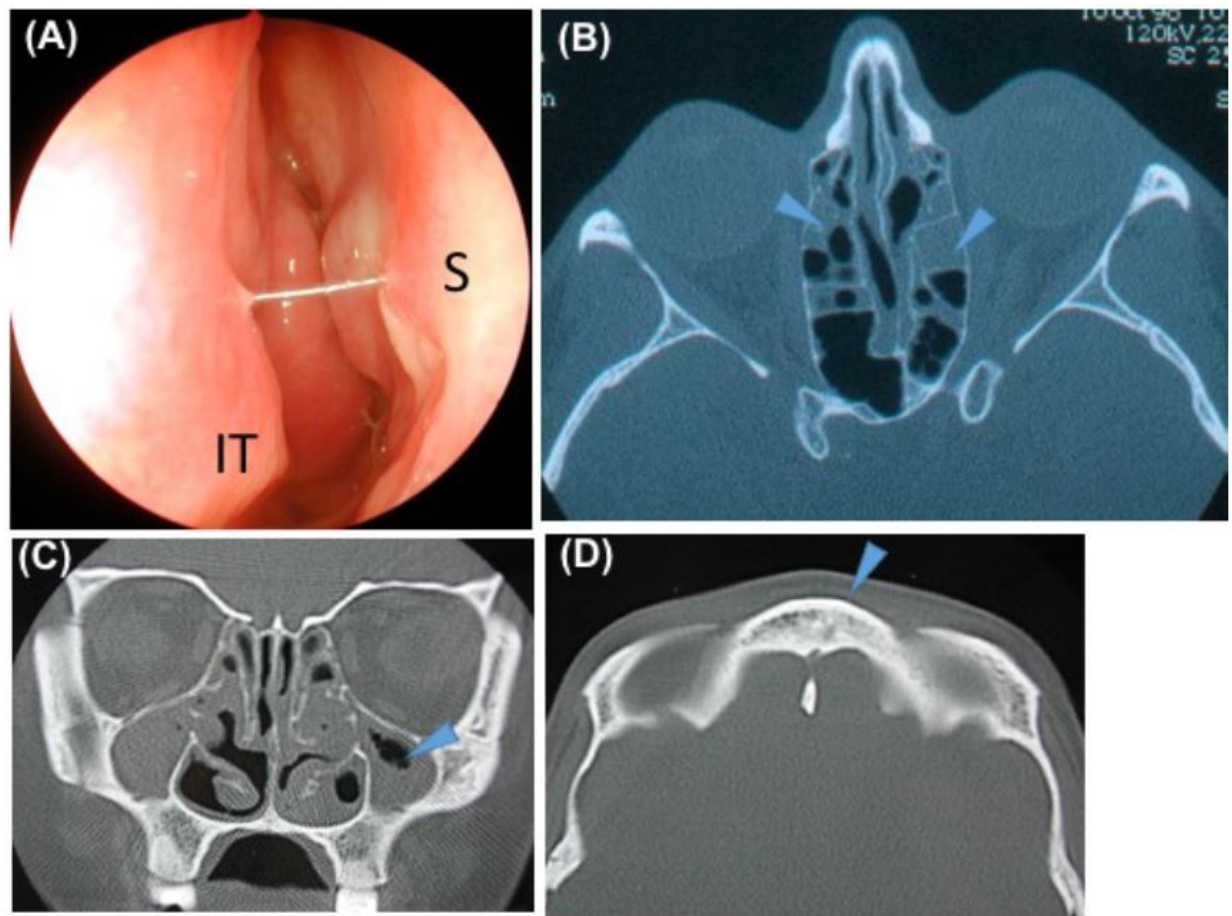

Figure 2. Typical nasal endoscopy and sinus computed tomography (CT) scan in an adult with primary ciliary dyskinesia PCD. (A) Typical nasal endoscopy (right side): secretions were sticky and thick, strung between the septum (S) and the inferior turbinate (IT). In a typical form, we observe oedema and congestive mucosa with or without polyps. (B) Sinus CT scan axial view: partial opacities of ethmoid cells. (C) Sinus CT scan coronal view: maxillary sinus hypoplasia. (D) Sinus CT scan axial view: frontal sinus agenesis. 


\subsection{Description of the Ear Disease}

Along with the sinonasal disease, a history of OME was reported in 58 patients $(90.7 \%)$ and a history of ventilation tube insertion during childhood was reported in 24 patients (37.5\%) (Table 3). One or more ear symptoms were present in 43 patients $(67.2 \%)$ with hearing loss being the most frequent ( $n=34$ or $53.1 \%$ of the patients). Upon examination, 19 patients $(29.6 \%)$ had normal bilateral eardrums. At least one abnormal eardrum was observed in 45 patients $(70.3 \%)$ (i.e., active OME or sequela of chronic otitis such as tympanic retraction, tympanosclerosis, perforation). Active OME was present in only $24 \%$ of eardrums. A pure tone audiogram was performed in 45 patients and hearing loss (air conduction $\geq 10 \mathrm{~dB}$ ) was observed in 30 patients (66.7\%). Among these, $46.7 \%$ had a pure conductive hearing loss, $16.7 \%$ had a pure sensorineural hearing loss, and $36.6 \%$ had a combined hearing loss. No patient had ear surgery (ventilation tube insertion or tympanoplasty) or hearing aids after PCD diagnosis.

Table 3. Ear and hearing disease at diagnosis in our reference center ( $n=64$ except when specified).

\begin{tabular}{ccc}
\hline & $\boldsymbol{n}$ & $\mathbf{\%}$ \\
\hline Symptoms $(n=64$ patients) & 34 & 53.1 \\
Hearing loss & 9 & 14.1 \\
Ear pain & 6 & 9.4 \\
Tinnitus & 5 & 7.8 \\
Otorrhea & & \\
Otoscopy (n=128 eardrums) & 53 & 41.4 \\
Normal & 31 & 24.2 \\
OME & 13 & 10.1 \\
Tympanic retraction & 8 & 6.2 \\
Perforation & 18 & 14 \\
Tympanosclerosis & 5 & 3.9 \\
Ventilation tubes & & \\
Audiogram $(n=90$ ears) & 33 & 36.7 \\
Normal & 28 & 31.1 \\
Conductive hearing loss & 16 & 17.8 \\
Combined hearing loss & 13 & 14.4 \\
Sensorineural hearing loss &
\end{tabular}

Abbreviations: OME $=$ otitis media with effusion.

\subsection{Correlation between Upper Airways Disease and Characteristics of PCD}

There wasn't any significant difference of the mean overall score of nasal symptoms according $\mathrm{nNO}(p=0.6), \mathrm{CBF}(p=0.5)$, ultrastructural phenotypes $(p=0.12)$ or lung function $(p=0.94)$.

Neither was any significant difference for the CT score according to the age ( $<40 \mathrm{vs} \geq 40$ years) $(p=0.85), \mathrm{CBF}(>8 \mathrm{~Hz}$ or $<8 \mathrm{~Hz})(p=0.76)$, ultrastructural phenotype $(p=0.5)$ lung function $\left(\mathrm{FEV}_{1}<\right.$ $70 \%$ or $\geq 70 \%)(p=0.86)$, or $\mathrm{nNO}(p=0.61)$.

In particularly, nasal disease (mean overall score of nasal symptoms and CT score) was more severe in the TEM group (absence of inner dynein arms with disorganization) than other groups (CC abnormalities and no detectable defect) without reaching significant difference.

No correlation was found between the presence of OME and age $(p=0.99)$, CBF $(p=0.36)$, ultrastructural phenotype $(p=0.16)$.

There was significantly more OME in patients with $\mathrm{FEV}_{1}<70 \%(p=0.01)$.

\section{Discussion}

To our knowledge, this is the largest study describing ENT disease in patients who started their follow-up in a PCD reference center as adults. Nearly all the patients had ENT symptoms since childhood, mainly rhinorrhoea and hearing loss. The nasal symptom score was higher in patients over 
40 years of age. Nasal endoscopy was abnormal in all patients except one and it revealed chronic rhinosinusitis with nasal polyps in a third of the patients. Nearly a third of the patients had normal eardrums, however, OME, which is consistently seen in childhood, was diagnosed in less than a quarter of the adults. Hearing loss (either conductive or sensorineural) was found in two-thirds of the patients who underwent an audiogram. ENT disease severity was not correlated to any characteristics of PCD (i.e., $\mathrm{nNO}, \mathrm{CBF}$, and ultrastructural phenotype). However, OME in adults could be a severity marker of lung function.

One limitation of our study is the retrospective collection of data, which may have introduced a bias in evaluating ENT disease in our study population. However, a standardized case report form was systematically completed by each senior investigator. Some complementary investigations such as CT scan, audiogram, and bacteriological culture were not systematically performed.

Sinonasal presentation of the disease in adults was similar to that in children but worsened with age. A history of chronic rhinosinusitis was always described in our PCD population. Only one patient had no previous history of rhinosinusitis and exhibited a normal nasal endoscopy (i.e., a 32-year-old man with hypofertility). In this patient, the diagnosis of PCD was confirmed by identification of a typical ultrastructural defect of cilia (absence of both dynein arms) and of causal mutations in the DNAAF 1 gene.

Almost all of the patients had an abnormal nasal endoscopy corresponding to chronic rhinosinusitis, even those with few symptoms. These findings contrast with the retrospective study by Noone et al. who reported sinusitis in $47 \%$ of adult patients with PCD [17]. However, their diagnosis was based only on previous sinus surgery or sinus radiographs. Another study of 44 adult patients with PCD, based on an auto-questionnaire to determine ENT clinical manifestations (with only a response rate of $46 \%$ ) reported recurring problems at the paranasal sinuses in $59 \%$ of all patients, and $69 \%$ of these patients needed corresponding surgical intervention [18]. A systematic nasal endoscopic examination, as performed in our ENT clinic, provides a more objective approach. A typical nasal sign in endoscopy is the presence of sticky secretions strung between the septum and the inferior turbinate. Nasal polyps in PCD have already been reported in the literature as occurring in $25 \%$ to $52 \%$ of adults [11,19] which is similar to our findings. The prevalence of nasal polyps in PCD is similar to cystic fibrosis (prevalence of 39-48\%) [20,21]. Nasal polyps in PCD differ from the classic eosinophilic sinonasal polyposis, since they are associated with oedema, congestive mucosa, and sticky or purulent secretions. Such an atypical subtype of rhinosinusitis is mainly found in rare conditions such as cystic fibrosis and immunodeficiency which represent the classical differential diagnosis of PCD [22,23].

Sinus CT scan analysis showed sinus hypoplasia and/or aplasia in around a third of our patients, which is lower than in the study by Pifferi et al. and El Sayed et al. (73\% and 56\% of abnormalities, respectively) [24,25]. As previously reported, sinus opacities were found in almost all our patients [26] but adults with PCD can show a normal sinus CT scan as described in our study.

However, sinus CT opacities were mainly incomplete. Consequently, as already described [17], the mean CT score was low, which contrasts with the reported score in non-PCD patients with chronic sinusitis and asthma [27].

Ear disease appears to be less severe in adults with PCD than in children. OME, which is present in nearly all children with PCD [4], was found in approximately one-quarter of our adult patients. This contrasts with a retrospective study by Anderson et al. [28] who found $68 \%$ of ears with OME in the age group $>17$ years $(n=33)$ but the mean (interval) age of the group was not given and could introduce a bias [28]. Ear disease would thus appear to be less frequent than sinonasal disease in adults. In our study, unlike children, very few adults complain of otorrhoea and earache which is in contrast with a study by Anderson et al. [28]. This difference could be explained by a higher percentage of patients with ventilation tubes the study by Anderson et al. than in our study (54\% versus 37.5\%, respectively). In our adult study, hearing loss measured with audiometry was present in half of the patients, which was in line with a previous questionnaire-based study [18]. Anderson et al. [28], noted that hearing significantly improved with increasing age, but considering their results in detail it 
showed that only air conduction improved while bone conduction worsened, as found in our study. Indeed, in our study, we found that the subtype of hearing loss is different in adults as compared with children. Adults tend to have sensorineural hearing loss (as in one third of the patients in our study) while children with PCD mainly have conductive hearing loss secondary to OME. The pathogenesis of sensorineural hearing loss in the adults is not clear. Presbyacusis was only observed in one patient who was 60 years old. Ototoxic adverse effects of routine PCD therapies such as aminoglycoside or macrolides could be involved, or the passage of bacterial toxins into the inner ear [29]. Lundman et al. demonstrated in chinchillas that Pseudomonas aeruginosa exotoxin A can cross the round window, causing irreversible hair cell loss [30]. Moreover, despite chronic otitis in childhood, no complications such as cholesteatoma were reported in our PCD cohort as in the literature [25] probably because of a different physiopathology. Interestingly, a significant correlation was found between the presence of OME and lung function in our study. This result needs to be confirmed but it could suggest that OME in an adult with PCD could be a severity marker of lung function and lead to closer follow-up and more aggressive treatment.

As compared with lower airway disease in PCD, the natural course of upper airway disease is less known in adults. We observed a significant worsening of sinusitis with age. For most patients, nasal surgery was performed early in the natural history of their ENT disease, and mainly before PCD diagnosis. In a recent adult study, $52 \%$ of patients had sinus surgery at least once [19]. When the PCD diagnosis was established, the type of sinonasal surgery focused on the inferior turbinates and ethmoid to improve nasal obstruction and rhinorrhoea [31]. It is important to note that sinonasal surgery could complicate nasal sampling for ciliary analysis and thus delay PCD diagnosis. After PCD diagnosis, very few patients underwent ENT surgery for chronic rhinosinusitis and none for ear disease.

This study highlights that ENT data could be used to propose a new specific adult clinical score to select patients for PCD diagnostic testing [32]. Indeed, the clinical score used in pediatric populations is probably less appropriate in adults. Moreover, retrospective clinical information data collected in adults are less relevant than data collected in children, especially concerning neonatal respiratory distress $[33,34]$.

\section{Conclusions}

This study has resulted in a change of daily practice in our centers. Firstly, in adults suffering from ENT symptoms since childhood, signs suggestive of PCD are: the presence of thick nasal secretion with or without polyps, OME, and hypoplasia or agenesis on the CT scan (even if sinus ventilation is normal or the CT score of sinus opacities is low). These signs are suggestive of a ciliary disorder and worth investigating. Secondly, considering the high proportion of sensorineural hearing loss, we systematically perform temporal bone imaging at diagnosis and audiometric follow-up, which can be intensified if the patient is prescribed potentially ototoxic antibiotics. Thirdly, our follow-up focuses more specifically on sinonasal symptoms control as a longitudinal reflection of sinusitis symptomatology, which is the primary cause of decreased quality of life and the primary outcome measure used for clinical decision-making. In our experience, nasal endoscopy is a secondary outcome measure (used for nasal obstruction evaluation and/or bacterial sampling of the middle meatus) and CT scan is never used as a follow-up exam.

This study opens a wide field of ENT-guided studies in order to: (i) improve PCD diagnosis in adults by establishing a screening score; (ii) to improve ENT management and follow-up (sinonasal surgery indications, monitoring of adult patients with OME, internal ear explorations); and (iii) to understand the relationship between ENT and pulmonary diseases.

Supplementary Materials: The following are available online at http://www.mdpi.com/2077-0383/8/5/619/s1, Table S1: PCD diagnostic tests.

Author Contributions: J.-F.P., A.C., E.E. participated in the study design, supervision, data analysis and writing of the article; E.B. participated in the data analysis and the interpretation and writing of the article; L.D. participated in the acquisition and interpretation of data and writing of the article; F.Z. participated in the data analysis and the 
interpretation and writing of the article; L.B., I.H., M.L., M.D.d.M., V.E., B.C., B.M. participated in acquisition of data and has approved the submitted version.

Acknowledgments: We are very sad to report the unexpected death of Issam Abd Alsamad, an outstanding pathologist who we would like to acknowledge for his involvement in PCD research for more than 20 years.

Conflicts of Interest: The authors declare no conflict of interest.

\section{Abbreviations}

$\begin{array}{ll}\text { OME } & \text { otitis media with effusion } \\ \text { PCD } & \text { Primary Ciliary Dyskinesia } \\ \text { KS } & \text { Kartagener Syndrome } \\ \text { SI } & \text { situs inversus } \\ \text { CF } & \text { cystic fibrosis } \\ \text { n (NO) } & \text { Nasal Nitric Oxide } \\ \text { CBF } & \text { ciliary beat frequency } \\ \text { FEV } & \text { forced expiratory volume } \\ \text { TEM } & \text { Transmission electron microscope } \\ \text { CT } & \text { computed tomography }\end{array}$

\section{References}

1. Bush, A.; Chodhari, R.; Collins, N.; Copeland, F.; Hall, P.; Harcourt, J.; Hariri, M.; Hogg, C.; Lucas, J.; Mitchison, H.M.; et al. Primary ciliary dyskinesia: Current state of the art. Arch. Dis. Child. 2007, 92, 1136-1140. [CrossRef]

2. Armengot Carceller, M.; Mata Roig, M.; Milara Paya, X.; Cortijo Gimeno, J. Primary ciliary dyskinesia. Ciliopathies. Acta Otorrinolaringol. Esp. 2010, 61, 149-159. [CrossRef]

3. Barbato, A.; Frischer, T.; Kuehni, C.E.; Snijders, D.; Azevedo, I.; Baktai, G.; Bartoloni, L.; Eber, E.; Escribano, A.; Haarman, E.; et al. Primary ciliary dyskinesia: A consensus statement on diagnostic and treatment approaches in children. Eur. Respir. J. 2009, 34, 1264-1276. [CrossRef]

4. Pruliere-Escabasse, V.; Coste, A.; Chauvin, P.; Fauroux, B.; Tamalet, A.; Garabedian, E.N.; Escudier, E.; Roger, G. Otologic features in children with primary ciliary dyskinesia. Arch. Otolaryngol. Head Neck Surg. 2010, 136, 1121-1126. [CrossRef]

5. Ceccaldi, P.F.; Carre-Pigeon, F.; Youinou, Y.; Delepine, B.; Bryckaert, P.E.; Harika, G.; Quereux, C.; Gaillard, D. [Kartagener's syndrome and infertility: Observation, diagnosis and treatment]. J. Gynecol. Obstet. Biol. Reprod. 2004, 33, 192-194. [CrossRef]

6. Majithia, A.; Fong, J.; Hariri, M.; Harcourt, J. Hearing outcomes in children with primary ciliary dyskinesia-A longitudinal study. Int. J. Pediatr. Otorhinolaryngol. 2005, 69, 1061-1064. [CrossRef]

7. Campbell, R.G.; Birman, C.S.; Morgan, L. Management of otitis media with effusion in children with primary ciliary dyskinesia: A literature review. Int. J. Pediatr. Otorhinolaryngol. 2009, 73, 1630-1638. [CrossRef]

8. Bush, A.; Cole, P.; Hariri, M.; Mackay, I.; Phillips, G.; O'Callaghan, C.; Wilson, R.; Warner, J.O. Primary ciliary dyskinesia: Diagnosis and standards of care. Eur. Respir. J. 1998, 12, 982-988. [CrossRef]

9. Papon, J.F.; Bassinet, L.; Cariou-Patron, G.; Zerah-Lancner, F.; Vojtek, A.M.; Blanchon, S.; Crestani, B.; Amselem, S.; Coste, A.; Housset, B.; et al. Quantitative analysis of ciliary beating in primary ciliary dyskinesia: A pilot study. Orphanet J. Rare Dis. 2012, 7, 78. [CrossRef]

10. Vallet, C.; Escudier, E.; Roudot-Thoraval, F.; Blanchon, S.; Fauroux, B.; Beydon, N.; Boule, M.; Vojtek, A.M.; Amselem, S.; Clement, A.; et al. Primary ciliary dyskinesia presentation in 60 children according to ciliary ultrastructure. Eur. J. Pediatr. 2013, 172, 1053-1060. [CrossRef]

11. Tamalet, A.; Clement, A.; Roudot-Thoraval, F.; Desmarquest, P.; Roger, G.; Boule, M.; Millepied, M.C.; Baculard, T.A.; Escudier, E. Abnormal central complex is a marker of severity in the presence of partial ciliary defect. Pediatrics 2001, 108, E86. [CrossRef]

12. Jackson, C.L.; Behan, L.; Collins, S.A.; Goggin, P.M.; Adam, E.C.; Coles, J.L.; Evans, H.J.; Harris, A.; Lackie, P.; Packham, S.; et al. Accuracy of diagnostic testing in primary ciliary dyskinesia. Eur. Respir. J. 2016, 47, 837-848. [CrossRef] 
13. Du Mayne, M.D.; Pruliere-Escabasse, V.; Zerah-Lancner, F.; Coste, A.; Papon, J.F. Polypectomy compared with ethmoidectomy in the treatment of nasal polyposis. Arch. Otolaryngol. Head Neck Surg. 2011, 137, 111-117. [CrossRef]

14. Coste, A.; Yona, L.; Blumen, M.; Louis, B.; Zerah, F.; Rugina, M.; Peynègre, R.; Harf, A.; Escudier, E. Radiofrequency is a safe and effective treatment of turbinate hypertrophy. Laryngoscope 2001, 111, 894-899. [CrossRef]

15. Hopkins, C.; Browne, J.P.; Slack, R.; Lund, V.; Brown, P. The Lund-Mackay staging system for chronic rhinosinusitis: How is it used and what does it predict? Otolaryngol. Head Neck Surg. 2007, 137, 555-561. [CrossRef]

16. Orlandi, R.R.; Wiggins, R.H., III. Radiological sinonasal findings in adults with cystic fibrosis. Am. J. Rhinol. Allergy 2009, 23, 307-311. [CrossRef]

17. Noone, P.G.; Leigh, M.W.; Sannuti, A.; Minnix, S.L.; Carson, J.L.; Hazucha, M.; Zariwala, M.A.; Knowles, M.R. Primary ciliary dyskinesia: Diagnostic and phenotypic features. Am. J. Respir. Crit. Care Med. 2004, 169, 459-467. [CrossRef]

18. Sommer, J.U.; Schafer, K.; Omran, H.; Olbrich, H.; Wallmeier, J.; Blum, A.; Hormann, K.; Stuck, B.A. ENT manifestations in patients with primary ciliary dyskinesia: Prevalence and significance of otorhinolaryngologic co-morbidities. Eur. Arch. Otorhinolaryngol. 2011, 268, 383-388. [CrossRef]

19. Frija-Masson, J.; Bassinet, L.; Honore, I.; Dufeu, N.; Housset, B.; Coste, A.; Papon, J.F.; Escudier, E.; Burgel, P.R.; Maitre, B. Clinical characteristics, functional respiratory decline and follow-up in adult patients with primary ciliary dyskinesia. Thorax 2017, 72, 154-160. [CrossRef]

20. Weber, S.A.T.; Iyomasa, R.M.; Correa, C.C.; Florentino, W.N.M.; Ferrari, G.F. Nasal polyposis in cystic fibrosis: Follow-up of children and adolescents for a 3-year period. Braz. J. Otorhinolaryngol. 2017, 83, 677-682. [CrossRef]

21. Henriksson, G.; Westrin, K.M.; Karpati, F.; Wikstrom, A.C.; Stierna, P.; Hjelte, L. Nasal polyps in cystic fibrosis: Clinical endoscopic study with nasal lavage fluid analysis. Chest 2002, 121, 40-47. [CrossRef]

22. Schwitzguebel, A.J.; Jandus, P.; Lacroix, J.S.; Seebach, J.D.; Harr, T. Immunoglobulin deficiency in patients with chronic rhinosinusitis: Systematic review of the literature and meta-analysis. J. Allergy Clin. Immunol. 2015, 136, 1523-1531. [CrossRef]

23. Coste, A.; Girodon, E.; Louis, S.; Pruliere-Escabasse, V.; Goossens, M.; Peynegre, R.; Escudier, E. Atypical sinusitis in adults must lead to looking for cystic fibrosis and primary ciliary dyskinesia. Laryngoscope 2004, 114, 839-843. [CrossRef]

24. Pifferi, M.; Bush, A.; Caramella, D.; Di Cicco, M.; Zangani, M.; Chinellato, I.; Macchia, P.; Boner, A.L. Agenesis of paranasal sinuses and nasal nitric oxide in primary ciliary dyskinesia. Eur. Respir. J. 2011, 37, 566-571. [CrossRef]

25. El-Sayed, Y.; al-Sarhani, A.; al-Essa, A.R. Otological manifestations of primary ciliary dyskinesia. Clin. Otolaryngol. Allied Sci. 1997, 22, 266-270. [CrossRef]

26. Boon, M.; Jorissen, M.; Proesmans, M.; De Boeck, K. Primary ciliary dyskinesia, an orphan disease. Eur. J. Pediatr. 2013, 172, 151-162. [CrossRef]

27. Razmpa, E.; Saedi, B.; Safavi, A. The effect of functional endoscopic sinus surgery on pulmonary improvement of controlled asthmatic patients with chronic sinusitis. Iran. J. Allergy Asthma Immunol. 2010, 9, 231-236.

28. Andersen, T.N.; Alanin, M.C.; von Buchwald, C.; Nielsen, L.H. A longitudinal evaluation of hearing and ventilation tube insertion in patients with primary ciliary dyskinesia. Int. J. Pediatr. Otorhinolaryngol. 2016, 89, 164-168. [CrossRef]

29. Da Costa, S.S.; Rosito, L.P.; Dornelles, C. Sensorineural hearing loss in patients with chronic otitis media. Eur. Arch. Otorhinolaryngol. 2009, 266, 221-224. [CrossRef]

30. Lundman, L.; Santi, P.A.; Morizono, T.; Harada, T.; Juhn, S.K.; Bagger-Sjoback, D. Inner ear damage and passage through the round window membrane of Pseudomonas aeruginosa exotoxin A in a chinchilla model. Ann. Otol. Rhinol. Laryngol. 1992, 101, 437-444. [CrossRef]

31. Roger, G.; Denoyelle, F.; Corré, A.; Escudier, E.; Tamalet, A.; Garabedian, E.N. Place de la chirurgie endonasale lors des dyskinésies ciliaires primitives. Ann. Otol. Rhinol. Laryngol. 2003, 120, 109-113. 
32. Behan, L.; Dimitrov, B.D.; Kuehni, C.E.; Hogg, C.; Carroll, M.; Evans, H.J.; Goutaki, M.; Harris, A.; Packham, S.; Walker, W.T.; et al. PICADAR: A diagnostic predictive tool for primary ciliary dyskinesia. Eur. Respir. J. 2016, 47, 1103-1112. [CrossRef]

33. Boon, M.; Smits, A.; Cuppens, H.; Jaspers, M.; Proesmans, M.; Dupont, L.J.; Vermeulen, F.L.; Van Daele, S.; Malfroot, A.; Godding, V.; et al. Primary ciliary dyskinesia: Critical evaluation of clinical symptoms and diagnosis in patients with normal and abnormal ultrastructure. Orphanet J. Rare Dis. 2014, 9, 11. [CrossRef] [PubMed]

34. Mullowney, T.; Manson, D.; Kim, R.; Stephens, D.; Shah, V.; Dell, S. Primary ciliary dyskinesia and neonatal respiratory distress. Pediatrics 2014, 134, 1160-1166. [CrossRef]

(C) 2019 by the authors. Licensee MDPI, Basel, Switzerland. This article is an open access article distributed under the terms and conditions of the Creative Commons Attribution (CC BY) license (http://creativecommons.org/licenses/by/4.0/). 